African Crop Science Journal by African Crop Science Society is licensed under a Creative Commons Attribution 3.0 Uganda License. Based on a work at www.ajol.info/ and www.bioline.org.br/cs DOI: http://dx.doi.org/10.4314/acsj.v26i2.9

\title{
YIELD AND STABILITY OF NEW COWPEA VARIETIES IN ZIMBABWE
}

\author{
P.M. MATOVA ${ }^{1,2}$ and E. GASURA ${ }^{1}$ \\ ${ }^{1}$ Crop Breeding Institute, Department of Research and Specialist Services, P. O. Box CY550, Causeway, \\ Harare, Zimbabwe \\ ${ }^{2}$ Department of Crop Science, University of Zimbabwe, P. O. Box MP 167, Mt Pleasant, Harare, Zimbabwe \\ Corresponding author: gasurae@yahoo.com, egasura@agric.uz.ac.zw
}

(Received 16 May, 2017; accepted 23 January, 2018)

\begin{abstract}
Cowpea (Vigna unguiculata [L.] Walp) is highly nutritious and fits well in smallholder crop-livestock farming systems of sub-Saharan Africa. Newly developed cowpea varieties need to be assessed for grain yield performance and stability across environments. Furthermore, a comprehensive understanding of the test environments is crucial in rationalising resources for breeding programmes. The objective of this study was to identify high yielding and stable cowpea genotypes, and determine the ideal (representative and discriminating) testing environments for cowpea in Zimbabwe. Fifteen cowpea genotypes were evaluated at 5 locations, for 2 years under rain-fed conditions. Combined analysis of variance for grain yield across locations and years showed highly significant $(\mathrm{P}<0.001)$ genotype $\mathrm{x}$ environment interaction $(\mathrm{GE})$. The variance component due to GE was 6 times larger than that of genotypes. Genotype plus GE biplot showed that environments studied were actually in one mega-environment; and Harare Research Station (HRS) was identified as desirable discriminating and representative environment. Genotypes G1, G11 and G3 were high yielding and more stable than the check varieties, G4 (CBC2) and G7 (CBC3). These genotypes are suitable for release; while HRS is recommended for culling inferior genotypes during early generation testing.
\end{abstract}

Key Words: Biplot, sub-Saharan Africa, Vigna unguiculata

\section{RÉSUMÉ}

Le niébé (Vigna unguiculata [L.] Walp) est hautement nutritif et bien adapté au système de production associant culture-animal de l'Afrique Sub-Saharienne. Des variétés nouvellement développéesont besoin d'être évaluées pour leur performance en grain et leur stabilité à travers des environnements. De plus, une bonne maîtrise des environnements à tester en rationalisant les ressources pour les programmes d'amélioration génétique. L'objective de cette étude était d'identifier les génotypes à haut rendement et stables, et de déterminer les environnements idéaux (représentatifs et discriminants) pour le niébé au Zimbabwe. Quinze génotypes du niébé ont été évalués dans 5 localités, pendant deux ans sous des conditions pluviales. Analyse combinée de variance pour le rendement en grain à travers les localités et années ont montré une interaction génotype $\mathrm{x}$ environnement (GE) significative $(\mathrm{P}<0.001)$. La composante de variance due à GE était 6 fois plus grande que celle des génotypes. Génotype plus GE biplot a montré que les environnements étudiés étaient évidemment dans un méga-environnement; et la station de recherche de Harare (HRS) était identifiée comme un environnement désirable discriminant et représentatif. Les génotypes G1, G11 et G3 étaient à haut rendement et plus stable que les variétés contrôles, G4 $(\mathrm{CBC} 2)$ et $\mathrm{G} 7$ (CBC3). Ces génotypes sont les plus appropriés pour délivrance, alors que HRS est recommandée pour faible sélection dans la génération précoce.

Mots Clés: Biplot, sub-Saharan Africa, Vigna unguiculata 


\section{INTRODUCTION}

Cowpea (Vigna unguiculata [L.] Walp) is a common grain legume cultivated in the semiarid tropics of Africa, mainly by smallholder farmers (Fatokun et al., 2002). The crop is mainly used as a source of food and feed. Cowpea, a legume, is rich in essential amino acids (Fatokun et al., 2002) especially, lysine and tryptophan that are frequently lacking in the cereal dominated diets of the resource-poor farmers. Furthermore, cowpea has the ability of improving soil fertility, owing to its nitrogen fixing ability and is an excellent crop for breaking disease cycles in relay farming, mixed farming and crop rotations (Fatokun et al., 2002).

In semi-arid areas, over $90 \%$ of smallholder farmers produce cowpea for household consumption and/or sale in local markets (Fatokun et al., 2002). However, most of the farmers struggle with unproductive soils, heavy pests and disease infestation, unreliable rainfall, and heat and drought stress, among other limiting factors (Nyamapfene, 1991; Fatokun et al., 2002; Rukuni et al., 2006). These stress conditions have caused variation in yield obtained by farmers. The Crop Breeding Institute (CBI) of the Ministry of Agriculture, Mechanisation and Irrigation Development of Zimbabwe, has developed cowpea varieties that are reportedly suitable for these diverse conditions in the country (CBI, 2012). However, identification of well adapted cowpea varieties is hampered by the presence of crossover genotype $\mathrm{x}$ environment interactions (GE) that are common in multienvironment trial (MET) data (Yan and Kang, 2003). Crossover GE is the differential performance of varieties grown across different environments and remains the greatest hindrance to meaningful progress in the breeding, evaluation and recommendation of crop varieties (Alwala et al., 2010).

Yan and Tinker (2006) stated that METs require many locations and years, yet the data they generate is usually not fully utilised. Other researchers demonstrated some of the uses of MET data in identification of genotypes with high mean performance and stability and delineation of mega-environments as well as identification of ideal testing environments (Yan and Tinker, 2006; Gauch, 2013). Some of these tools can be exploited for cowpea MET data in the sub-Saharan Africa. For example, use of many locations over years result in increased cost of evaluation, thus burdening the cowpea breeding programmes that are already constrained by funds. Test environment analysis will help in rationalising the scarce resources; while delivering new varieties in a shorter time.

Setimela et al. (2005) grouped the crop production environments in southern Africa, and Zimbabwe was shown to have 5 agroecological environments that represent a major fraction of the sub-Saharan region (Rukuni $e t$ al., 2006). In line with this, Zimbabwe (as a representative of the sub-Saharan region) was shown to have 5 different agro-ecological zones (Nyamapfene, 1991; Rukuni et al., 2006). In practical terms, for variety release, most committees in sub-Saharan Africa require at least five different locations for two cropping seasons to recommend a variety for release (Setimela et al., 2005). In order to reduce on the costs of evaluation, not every experimental variety must be taken for MET.

Therefore, where a single-mega environment exists, early generation testing can be done at a single location that is both discriminating and representative of the other test locations. Furthermore, use of uncorrelated and discriminating sites saves scarce resources by concentrating only on the environments that are informative during cowpea evaluation (Yan and Kang, 2002).

There are several reported methods of studying crossover GE; which include use of regression methods, the additive main effect and multiplicative interaction (AMMI) biplots, and the genotype plus GE (GGE) biplots (Becker and Leon, 1988; Yan and Tinker, 2006; Gauch, 2013). Gauch (2013) showed 
important steps in MET data analysis that involve model diagnostics, mega-environment delineation and cultivar recommendation. To achieve these steps, a combination of analysis of variance and biplot analysis has proved to be useful (Yan and Kang, 2002; Gauch, 2006; 2013). The use of biplot analysis has recently increased due to its simplicity and huge amount of information that can be derived (Yan and Kang, 2003; Yan and Tinker, 2005; Gauch, 2006; Yan and Tinker, 2006; Gauch et al., 2008). The AMMI biplot displays the additive main effects of genotypes and environments, and their multiplicative interactions (Gauch, 2006; Gauch et al., 2008).

In the recent past the importance of GGE biplot was demonstrated in selecting ideal (representative and discriminating) testing locations, selection of stable and high yielding varieties, and associating varieties with given traits (Yan and Hunt, 2001; Yan and Kang, 2003; Yan and Tinker, 2005; 2006). The GGE approach removes the environment from the model and displays genotype effects with the GE of MET data (Yan and Kang, 2003; Yan and Tinker, 2006). The GGE biplot method allows visual examination of the relationships occurring among the environments, genotypes and the GE interactions in MET data graphically in an effective and convenient way (Yan and Kang, 2003; Yan and Tinker, 2006). The objective of this study was to use the GGE biplot to identify high yielding and stable cowpea genotypes in diverse environments, and to determine informative cowpea testing locations for future cowpea breeding programmes.

\section{MATERIALS AND METHODS}

Cowpea germplasm and study sites. Thirteen cowpea lines in the advanced breeding stages, and 2 check varieties, namely $\mathrm{G} 4$ (CBC2) and G7 (CBC3) (Table 1) were evaluated by the Crop Breeding Institute (CBI) for grain yield at 5 different locations in Zimbabwe, during the 2011/12 and 2012/13 cropping years. The description of the test locations are given in Table 2. These locations represent major production environments in Zimbabwe. The five locations and two years resulted in 10 environments based on the location-year combinations. All the promising lines were developed by CBI. The 2 check varieties (CBC2 and $\mathrm{CBC} 3$ ) were released by $\mathrm{CBI}$ in 2003 based on high grain yield and wide adaptation in the region.

Experimental design and crop management. The 15 cowpea genotypes were planted in a randomised complete block design, with 4 replications at all locations. A plot consisted of 4 rows that were $3 \mathrm{~m}$ long, with inter-row spacing of $45 \mathrm{~cm}$ and in-row spacing of $15 \mathrm{~cm}$. The seeds were planted at a depth of $5-7 \mathrm{~cm}$. The seed planted was treated with a fungicide, Thiram $80 \% \mathrm{WP}$, at a rate of $70 \mathrm{~g} 100$ per kg to control damping off diseases. Compound D fertiliser (7: 14: 7 ratio of NPK) was applied before planting, at a rate of $100 \mathrm{~kg} \mathrm{ha}^{-1}$. Ammonium nitrate fertiliser $(34.5 \% \mathrm{~N})$ was applied towards flowering at a rate of $50 \mathrm{~kg} \mathrm{ha}^{-1}$ at all locations. Hand weeding was done twice, at 3 and 6 weeks after planting, at each location. Sapsucking and leaf chewing insects were controlled by spraying with diamethoate, karate and thionex; while copper-oxychloride was used for fungal and bacterial diseases control. All applications were based on the manufacturers recommended rates (Fatokun et al., 2002).

Data collection. Pods were carefully handpicked after reaching 95\% physiological maturity, from the 2 inner rows, and put into sacks for further drying in a shed. The dried pods were threshed manually and the chuff and extraneous material were removed using a locally made winnowing basket. Grain yield was recorded per plot and then converted to $\mathrm{kg} \mathrm{ha}^{-1}$. 
TABLE 1. Characteristics of cowpea germplasm evaluated at five locations during the 2011/12 and 2012/13 cropping years in Zimbabwe

\begin{tabular}{lllc}
\hline Genotype code & Genotype name & Seed colour & Average seed weight $\left(\mathrm{g} \mathrm{seed}^{-1}\right)$ \\
\hline G1 & C/87/6/13 & Cream & 0.20 \\
G2 & C/59/6/19 & Reddish brown & 0.15 \\
G3 & C/95/6/9 & Cream & 0.20 \\
G4 & CBC2 & Reddish brown & 0.15 \\
G5 & C/70/6/10 & Reddish brown & 0.15 \\
G6 & C/59/6/6 & Cream & 0.15 \\
G7 & CBC3 & Cream & 0.15 \\
G8 & C/23/5/20 & Light cream & 0.20 \\
G9 & C/93/4/3 & Red & 0.15 \\
G10 & C/85/6/4 & Brown speckled & 0.20 \\
G11 & C/69/6/5 & Reddish brown & 0.15 \\
G12 & C/59/6/18 & Reddish brown & 0.12 \\
G13 & $\mathrm{C} / 83 / 4 / 6$ & Reddish brown & 0.15 \\
G14 & C/58/6/5/2 & Reddish brown & 0.15 \\
G15 & $\mathrm{C} / 59 / 6 / 23$ & Cream & 0.15 \\
\hline
\end{tabular}

Source: Cowpea Breeding Programme, Crop Breeding Institute, Ministry of Agriculture, Mechanization and Irrigation Development, Zimbabwe

Data analysis. Genotype $\mathrm{x}$ location $\mathrm{x}$ year analysis of variance (ANOVA) was performed on cowpea grain yield, using a mixed model (where genotypes and locations were fixed; while years were random) in GenStat software version 14 (GenStat, 2011). The following model for the combined ANOVA was used:

$\mathrm{Y}_{\mathrm{ijkl}}=\mu+\mathrm{r}_{\mathrm{l}}(\mathrm{pt})_{\mathrm{jk}}+\mathrm{g}_{\mathrm{i}}+\mathrm{p}_{\mathrm{j}}+\mathrm{t}_{\mathrm{k}}+(\mathrm{gp})_{\mathrm{ij}}+(\mathrm{gt})_{\mathrm{ik}}+$ $(p t)_{j k}+(g p t)_{i j k}+e_{i j k l}$

Where:

$Y_{i j k l}$ was the response of the $i^{\text {th }}$ genotype in the $\mathrm{j}^{\text {th }}$ location and the $\mathrm{k}^{\text {th }}$ year in the $\mathrm{l}^{\text {th }}$ replication, $\mu$ was the grand mean and $r_{1}(p t)_{j k}$ was the effect of the $\mathrm{l}^{\text {th }}$ replication within locations and years. $\mathrm{g}_{\mathrm{i}}, \mathrm{p}_{\mathrm{j}}$ and $\mathrm{t}_{\mathrm{k}}$ were the main effects of the genotype, locations and years, $(\mathrm{gp})_{\mathrm{ij}}$, $(\mathrm{gt})_{\mathrm{ik}}$, $(\mathrm{pt})_{\mathrm{jk}}$ were the first order interactions and $(\mathrm{gpt})_{\mathrm{ijk}}$ is the second order interaction, and $\mathrm{e}_{\mathrm{ijkl}}$ was the micro-environmental deviation within locations and years (pooled error term). The terms $\mathrm{i}=1,2,3 \ldots 15 ; \mathrm{j}=1,2 \ldots 5 ; \mathrm{k}=1,2$; and $l=1,2,3$.

The appropriate F-test for a mixed model that involves fixed genotypes and locations and random years was carried out as described by McIntosh (1983) and Moore and Dixon (2015). The assumption used for the combined experiments is that the effect of random interactions sum to zero across each level of a fixed factor (Moore and Dixon, 2015). In brief, the mean squares for genotypes, genotypes $\mathrm{x}$ locations, genotypes $\mathrm{x}$ years and genotypes $\mathrm{x}$ locations $\mathrm{x}$ years were tested against the pooled error mean square; while locations, years and location $\mathrm{x}$ years were tested against the mean square of replications within locations and years (McIntosh, 1983).

The variance components attributed to locations $\left(\delta^{2} \mathrm{l}\right)$, years $\left(\delta^{2} \mathrm{y}\right)$, locations $\mathrm{x}$ years $\left(\delta^{2} \mathrm{ly}\right)$, genotypes $\left(\delta^{2} \mathrm{~g}\right)$, genotypes $\mathrm{x}$ location $\left(\delta^{2} \mathrm{gl}\right)$, genotypes $\mathrm{x}$ years $\left(\delta^{2} \mathrm{gy}\right)$, genotypes $\mathrm{x}$ locations $\mathrm{x}$ years $\left(\delta^{2}\right.$ gly $)$ and random error $\left(\delta^{2} \mathrm{e}\right)$ were estimated by solving the equations formed by equating the mean squares to their respective expected mean squares (McIntosh, 1983; Moore and Dixon, 2015). The variance component due to environments (location $\mathrm{x}$ year combinations) was estimated by summing up $\delta^{2} 1, \delta^{2} y$ and $\delta^{2} 1 y$; while the variance component due to genotype $\mathrm{x}$ environment $\left(\delta^{2}\right.$ ge) was obtained by summing up $\delta^{2} \mathrm{gl}, \delta^{2} \mathrm{gy}$ 
and $\delta^{2}$ gly. The broad sense coefficients of genetic determination (broad sense heritability based on fixed genotypes) on a single plot basis, single environment basis and across environments basis were estimated as:

$\delta^{2} \mathrm{~g} /\left(\delta^{2} \mathrm{~g}+\delta^{2} \mathrm{gl}+\delta^{2} \mathrm{gy}+\delta^{2} \mathrm{gly}+\delta^{2} \mathrm{e}\right) ; \delta^{2} \mathrm{~g} /$ $\left(\delta^{2} \mathrm{~g}+\delta^{2} \mathrm{gl}+\delta^{2} \mathrm{gy}+\delta^{2} \mathrm{gly}+\delta^{2} \mathrm{e} / \mathrm{nr}\right.$ and $\delta^{2} \mathrm{~g} /$ $\left(\delta^{2} \mathrm{~g}+\delta^{2} \mathrm{gl} / \mathrm{nl}+\delta^{2} \mathrm{gy} / \mathrm{ny}+\delta^{2} \mathrm{gly} / \mathrm{nly}+\delta^{2} \mathrm{e} / \mathrm{nylr}\right.$, respectively

Where:

$\mathrm{nr}=$ number of replications, $\mathrm{nl}=$ number of locations, ny $=$ number of years, nly $=$ number of location $x$ year combinations and nylr is the number of years $\mathrm{x}$ location $\mathrm{x}$ replications. The two years and five location combinations (Table 2) resulted into 10 environments.

In order to determine the number of principal components to retain during GGE biplot analyses, a post-dictive evaluation was done for model fitting, using the Gollob (1968) F-test (Zobel et al., 1988; Dias et al., 2003; Gauch, 2013). A GGE-2 biplot analysis (Yan and Tinker, 2006) was done using Genstat Software version 14 (GenStat, 2011). The GGE biplot model was described by Yan and Hunt (2001) and Yan and Kang (2002) as:

$\mathrm{Y}_{\mathrm{ij}}-\mu-\beta_{\mathrm{j}}={ }^{\mathrm{k}} \Sigma_{1=1} \lambda \boldsymbol{\xi}_{\mathrm{il}} \eta_{\mathrm{j} 1}+\varepsilon_{\mathrm{ij}}$

Where:

$Y_{i j}$ is the mean yield of the $i^{\text {th }}$ genotype in the $j^{\text {th }}$ environment, $\mu$ is the grand mean, $\beta$ is the main effect of the environment $j, \lambda_{1}$ is the singular value of the $\mathrm{l}^{\text {th }}$ principal component and $k=2$ in this case, $\xi_{\mathrm{il}}$ is the eigen vector of the genotype $i$ for PC $l, \eta_{\mathrm{Ij}}$ is the eigen vector of environment $j$ for PC $l, \varepsilon_{\mathrm{ij}}$ is the residual associated with genotype $i$ in the environment $j$. Based on this model, the results of all biplots presented in this work are mainly environment centered.

The existence of the crossover interactions was checked using the Gail-Simon test (Baker, 1988). The which-won-where scatter biplot,

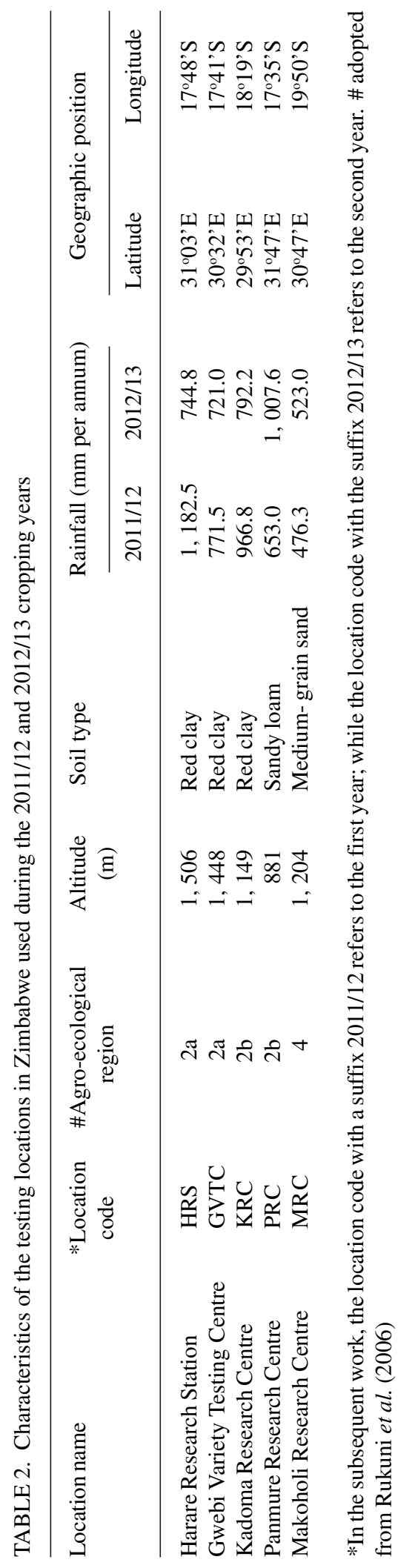


genotype comparison biplot, and the location comparison biplot were generated using the appropriate singular value partitioning (SVP) methods (Yan and Kang, 2002). In the scatter biplot, the polygon view displaying the whichwon-where pattern was formed by connecting the genotype markers furthest away from the biplot origin such that the polygon contained all other genotypes (Yan and Kang, 2002). The polygon was then dissected by sectors running from the biplot origin. Visualisation of the mean and stability of genotypes using a genotype comparison biplot was achieved by drawing an average environment coordinate (AEC) that is represented by a small circle. A line that passes through the biplot origin and the AEC was drawn followed by a perpendicular line. For the analyses of test location, the location vectors were drawn from the biplot origin to the markers of the location (Yan and Tinker, 2006).

\section{RESULTS}

Heritability estimates. There were highly significant $(\mathrm{P}<0.05)$ cowpea grain yields $(\mathrm{P}<0.001)$ for years, locations, year $\mathrm{x}$ location, genotype, and location x genotype (Table 3 ). Significant differences $(\mathrm{P}<0.01)$ were also found on year $\mathrm{x}$ genotype and year $\mathrm{x}$ location $x$ genotype (Table 3). Environments had the largest $(77.4 \%)$ contribution to the total variance, followed by the error at 15.9 and GE at 5.8\%; while the genotypes contributed the least $(0.9 \%)$. The variance component of GE was 6 times larger than that of genotypes. The broad sense coefficient of genetic determination equivalent of broad sense heritability for fixed genotypes, was 3.9, 8.4 and $35.4 \%$ on single plot basis, single environment basis and across environments basis, respectively.

Genotypes, years and locations. There were significant differences $(\mathrm{P}<0.05)$ on the main effects of genotypes, years and locations (results not shown). Grain yield of the cowpea genotypes evaluated across locations and years ranged from 1, 025 to $3,000 \mathrm{~kg} \mathrm{ha}^{-1}$. Across years analysis of grain yield data showed that year one was better than year two, with a mean grain yield of 2, $379 \mathrm{~kg} \mathrm{ha}^{-1}$ compared to the latter which had $1,707 \mathrm{~kg} \mathrm{ha}^{-1}$. The results also showed that location HRS had the highest mean yield (3, $\left.646 \mathrm{~kg} \mathrm{ha}^{-1}\right)$, followed by PRC (2, $\left.193 \mathrm{~kg} \mathrm{ha}^{-1}\right)$ KRS $\left(1,984 \mathrm{~kg} \mathrm{ha}^{-1}\right)$, GVTC $\left(1,358 \mathrm{~kg} \mathrm{ha}^{-1}\right)$ and lastly, MRS (1, $036 \mathrm{~kg}$ ha $\left.^{-1}\right)$.

Which-won-where pattern for cowpea genotypes. The Gollob (1968) F-test showed that the two principal components of

TABLE 3. Analysis of variance for cowpea grain yield evaluated across five locations during the 2011/12 and 2012/13 cropping years in Zimbabwe

\begin{tabular}{lcrrrr}
\hline Source of variation & $\begin{array}{c}\text { Degrees } \\
\text { of freedom }\end{array}$ & $\begin{array}{c}\text { Mean } \\
\text { square } \\
\text { values }\end{array}$ & $\begin{array}{l}\text { F- } \\
\text { probability }\end{array}$ & $\begin{array}{r}\text { Variance } \\
\text { component }\end{array}$ & $\begin{array}{c}\text { Variance } \\
\text { component } \\
\text { as } \% \text { of total } \\
\text { variance }\end{array}$ \\
\hline Year & 1 & 67804681 & $<.001$ & 224255.1033 & 11.2 \\
Location & 4 & 122842302 & $<.001$ & 1019284.6 & 51.0 \\
Year x location & 4 & 18674382 & $<.001$ & 302437.2 & 15.1 \\
Environments (replications) & 30 & 528150 & 0.017 & - & - \\
Genotype & 14 & 1030072 & $<.001$ & 17792.35 & 0.9 \\
Year x genotype & 14 & 790080 & 0.002 & 23585.1 & 1.2 \\
Location x genotype & 56 & 600688 & $<.001$ & 35288.75 & 1.8 \\
Year x location x genotype & 56 & 543244 & 0.002 & 56216.5 & 2.8 \\
Residual & 420 & 318378 & - & 318378 & 15.9 \\
\hline
\end{tabular}


the biplot were significant and, thus could explain most of the variation $(69.6 \%)$ in the 2-way data, with $\mathrm{PC} 1$ explaining $50.2 \%$ and PC2 explaining 19.4\% (Fig. 1). Figure 1 displayed a five sided polygon with five sectors. Sector 1 had G10 as the winning genotype and three environments (MRC-2012/ 13; PRC-2012/13 and HRS-2012/13) fell in this sector. Sector 2 had genotype G1 as the winning genotype and includes most environments (Fig. 1). Genotype G12 was the winning genotype for sector 3 and environment HRS-2011/12 fell in this sector.
Sectors 4 and 5 had no environments in them, but contained genotypes G4 (CBC2) and G7 (CBC3), respectively. The biplot shows 3 mega-environments that are overlapping and intersecting at the biplot origin (Fig. 1).

\section{Comparison of cowpea genotypes based on} the biplot analysis. Genotype G1 is located in the innermost concentric circle of the GGE biplot; followed by G11 and G3 (Fig. 2). Most genotypes had above average yield except G4 (CBC2), G7 (CBC3), G8 and G14 which had below average yield (Fig. 2).

Total $-69.62 \%$

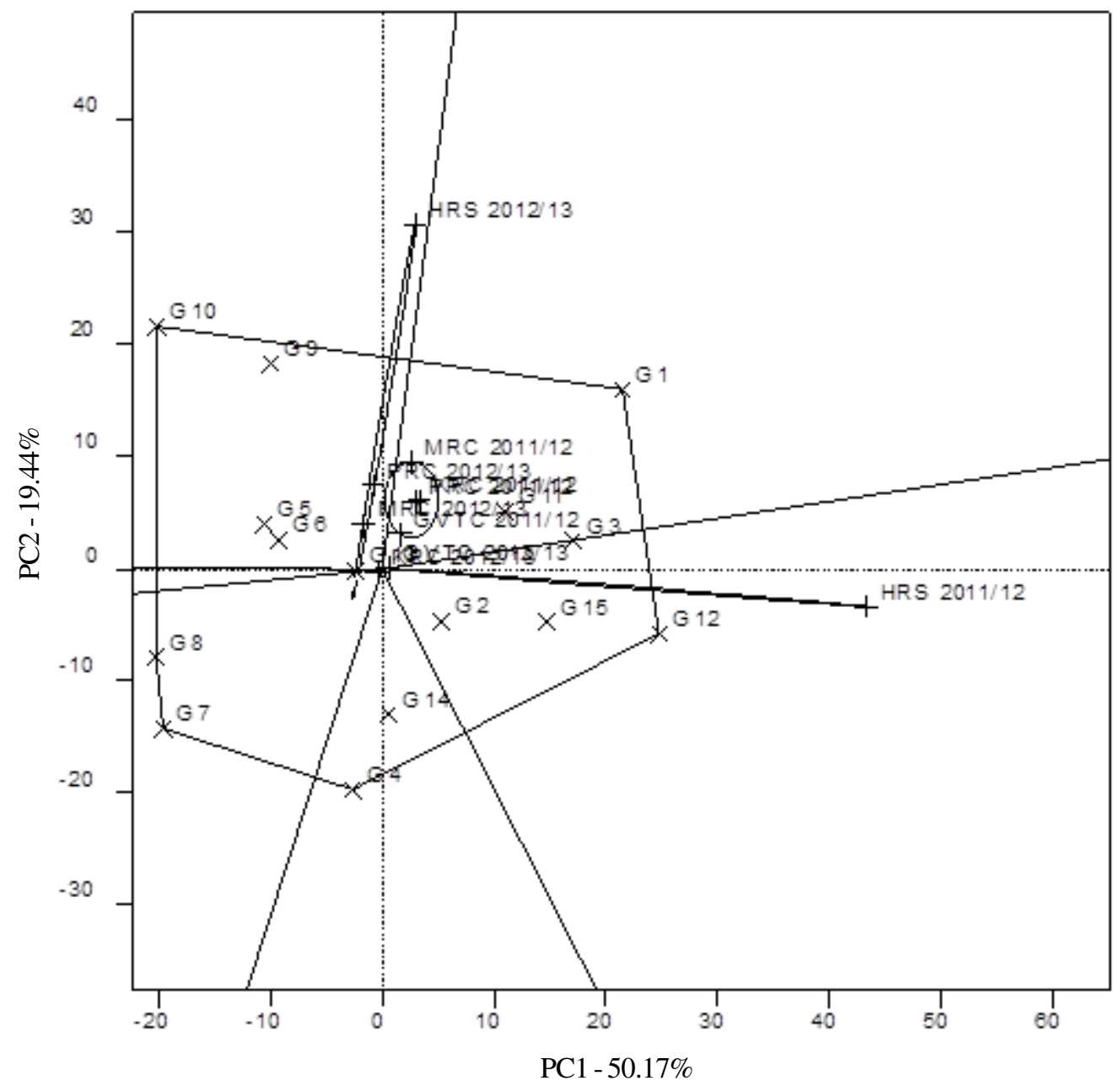

Figure 1. The which-won-where and mega-environment delineation biplot for the 15 cowpea genotypes evaluated in five locations in Zimbabwe for two years. The biplot was produced based on symmetric focused SVP, no scaling, no transformation and the data were environment centred. 


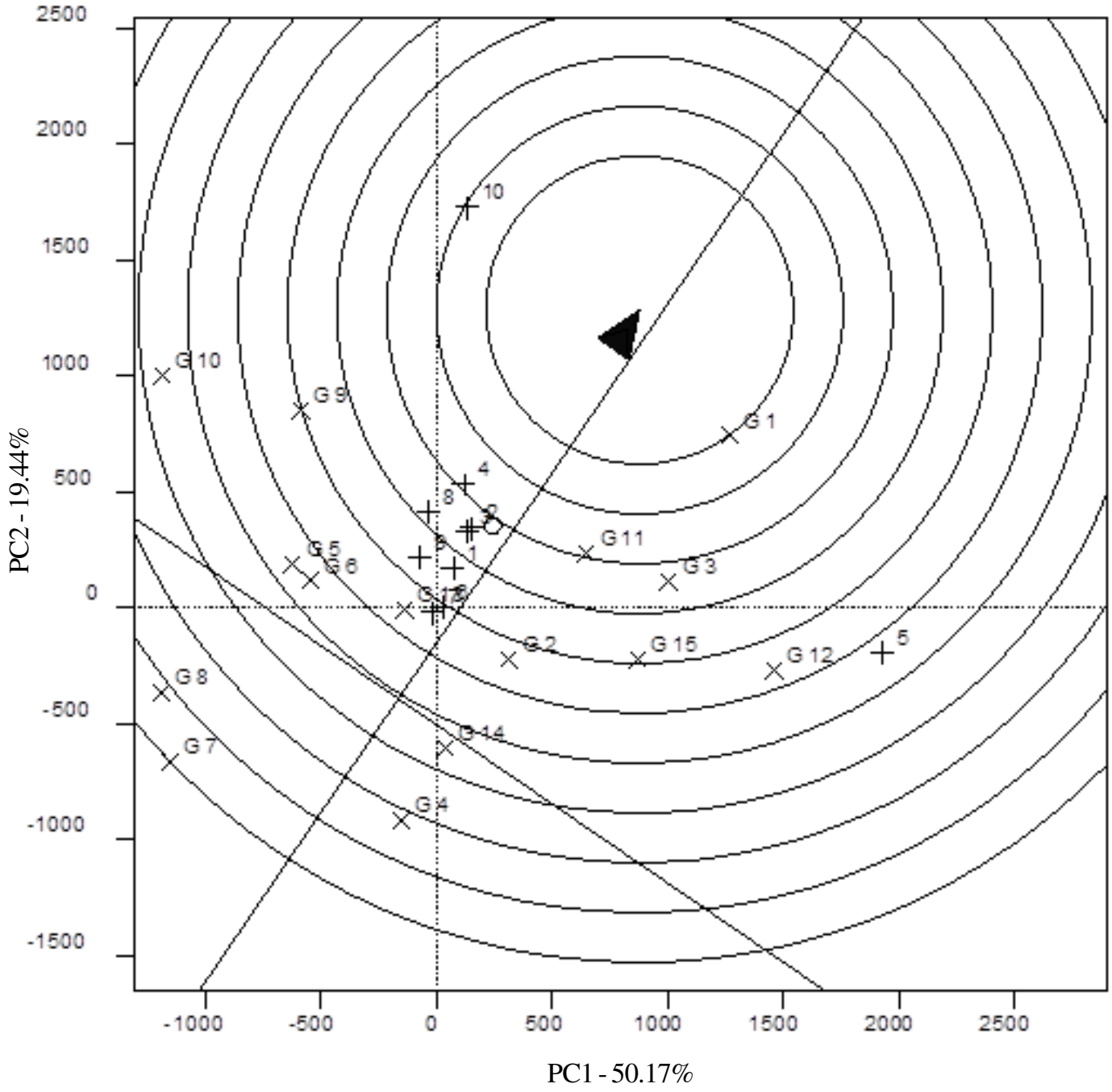

Figure 2. Cowpea genotypes comparison biplot showing the best genotypes based on mean yield performance and stability across 10 environments (five locations and two years) in Zimbabwe. To avoid congesting the graph, the environments are numbered 1-10 while genotypes are shown by their codes. The biplot was produced based on genotype focused SVP, no scaling, no transformation and the data were environment centred.

Test location evaluation. Locations HRS and GVTC (Table 1) had the longest imaginary vectors from the biplot origin (Fig. 3). These two locations were also separated by an angle close to $90^{\circ}$; while the other locations had short vector lengths (clustered near the biplot origin), separated by acute angles. Location GVTC had large absolute PC2 scores and small absolute PC1; while location HRS was characterised having large absolute PC1 scores and small PC2 scores (Fig. 3).

\section{DISCUSSION}

Variance components and heritability estimates. Environments (locations, years and locations $x$ years) contributed most to the total variation in MET in this study. This was 


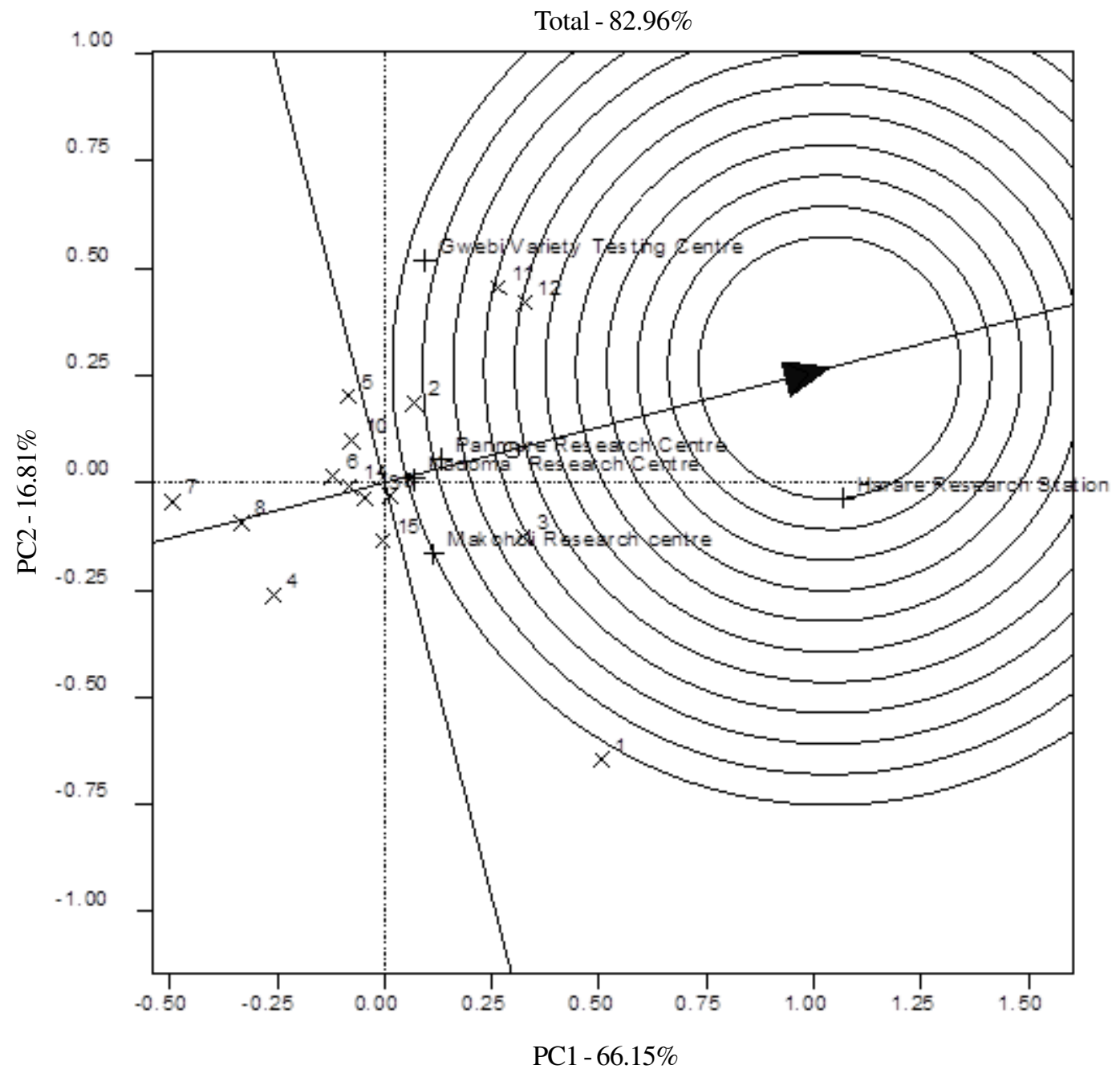

Figure 3. Test location evaluation based on the discriminating, location correlation and most representativeness. The biplot was produced based on location focused SVP, no scaling, no transformation and the data were location centred. To avoid congesting the graph, the genotypes are numbered 1-15 while locations are shown by their names.

mainly due to the fact that the intrinsic factors (biotic stresses, soils, temperature and rainfall) found at each location were highly variable (Rukuni et al., 2006). In terms of yield, the locations could be ranked as Harare $>$ Pannure $>$ Kadoma $>$ Gwebi $>$ Makoholi. In line with this, Zimbabwe is known to have 5 different agro-ecological zones (Nyamapfene, 1991; Rukuni et al., 2006) that are diverse in physical properties such as soils, rainfall and temperature. Variations in the unpredictable factors such as rainfall and temperature always vary across years, thus contributing to the large variance component due to years. Indeed, in this study there was relative more rainfall in the year 2011/12 than in the year 2012/2013 (Table 2). This variation in rainfall also resulted in year 2011/12 having more grain yield than year 2012/13.

Importance of genotype by environment interaction. A large genotype by environment 
interaction (GE) which was 6 times more than the genotypic variance (Table 3 ) shows that cultivar ranking changes with location, thus complicating selection. Furthermore, this GE was of crossover type as based on the SimonGail test (Baker, 1988). Crossover, GE reflects a situation, whereby different cowpea genotypes are winning in different environments (Baker, 1988). When GE is of crossover type and larger than genotypic variance, heritability is reduced, especially at single plot basis. When heritability is reduced, selection efficiency is lowered, since the observed grain yield values will not reflect the true genotypic value (Annicchiarico et al., 2000). This makes selection and recommendation of suitable varieties difficult (Caliskan et al., 2007) across the cowpea growing environments. In this case, heritability can be improved by increasing the number of replications, locations, and years (Casanoves et al., 2005).

In this study, heritability was improved from 4 to $35 \%$, with a shift from single plot to across environment means. In this regard, it is clear that increasing the number of locations and years improves heritability, but is coupled to an increase in the cost of evaluation. Increasing the cost of evaluation is detrimental, especially for government departments with little resources channeled to breeding activities.

Large GEs also confound the actual contribution of the main effects and the effect of GE. When the environment main effects have large contribution to the total observed variance, it suggests that the management of the environments to suit cowpea production would be logical (Bernardo, 2002). However, given the fact that resource-poor farmers cannot afford effective management of the environments, and the fact that it is difficult to manage the unpredictable factors associated with different years, the ideal option is to develop cultivars that can be high yielding and stable across locations and years.
The which-won-where pattern and megaenvironment analysis. Model diagnostics with the Gollob (1968) F-test showed that the GGE biplot could capture much of the variation (69.4\%) of the genotypes and GE (Fig. 1). Yang et al. (2009) highlighted that use of the GGE-2 biplot is suitable when the GE captures at least $60 \%$; while the genotypes captures at least $5 \%$ of the total variation. This condition has been met in this study, and thus supports the use of the GGE-2 biplot. The GGE-2 biplot based on combined data proved the existence of crossover GE, where different genotypes were winning in different environments (Fig. 1). When different cultivars win in different environments (Fig. 1), it suggest the existence of different mega-environments (Yan and Kang, 2003; Yan and Tinker, 2006). However, the which-won-where biplot for individual years (2011/12 and 2012/13) were nonrepeatable, and the mega-environments were overlapping and dissecting each other. Yan and Kang (2002) and Yan et al. (2007) explained such situation to be having a single, but complex mega-environment. The existence of one mega-environment for cowpea means that the cowpea breeding programme should not concentrate on breeding for specific adaptation; instead the programme should focus on breeding for wide adaptation. Yan et al. (2007) reported that when a single, but complex mega-environment exists, the strategy is to select a set of varieties on the basis of mean performance and stability using MET data for production across this megaenvironment.

Cultivar ranking based on mean yield and stability. GGE-2 biplot ranked genotypes based on their yield and stability (Fig. 2). The AEC abscissa separated genotypes with below average grain yields, from those that had above average grain yield potential. The average grain yield was 2, $043 \mathrm{~kg} \mathrm{ha}^{-1}$ (results not shown). However, yield above the mean alone is not good enough for cultivar selection, but 
cultivars should be stable and perform much better than the check varieties (Kaya et al., 2006). When the which-won-where pattern is non-repeatable over years, thus representing one complex mega-environment, Yan and Kang (2003) reported that cultivar evaluation should be based on mean yield and stability simultaneously. The GGE-2 biplot showed that in terms of high yield and stability, the cowpea genotypes could be ranked as G1>G11>G3 . Interestingly, these genotype performed much better than the two checks, G4 (CBC2) and G7 (CBC3). This shows a huge genetic gain in the cowpea breeding programme at the Crop Breeding Institute. These identified varieties are recommended for release in Zimbabwe. Genotypes with high and stable yield will enable farmers to secure harvests and allow profitability to breeding and marketing institutions.

Test environment analysis. Location HRS had both large absolute PC1 scores and small absolute PC2 scores (Fig. 2). This shows that this location is ideal for cowpea evaluation. Yan and Tinker (2005) and Yan and Tinker (2006) demonstrated that the ideal testing location should be characterised by both the large discriminating power (large PC1 scores) and the most representativeness (small PC2 scores). Location HRS is the most representative and discriminating among locations used in this study. The PC1 scores (location vectors from the biplot origin) are related to the standard deviation within the location and, hence showing the discriminating ability of the location (Yan and Kang, 2003). Location GVTC is discriminating, but not representative of the other locations. The ideal testing location (HRS in this case) can be used for early generation variety evaluations in Zimbabwe. This strategy will help save time and trial costs, since the huge number of genotypes normally present in early generations will be evaluated more efficiently and cheaply at this site (HRS) where the breeding programme is housed. Identification of HRS a high potential location as the most ideal testing environment in this study (Fig. 3) concurs with Cooper and DeLacy (1994), who reported that high potential environments were more representative and discriminating than the low potential environments. Identification of only one mega-environment also means that variety evaluation will not necessarily have to be conducted in all the population of testing environments studied. A few locations can be chosen for variety evaluation and these will represent the rest of the mega-environment (Blanche and Myers, 2006).

\section{CONCLUSION}

There is a large GE interaction in cowpea multienvironment trial (MET) data in Zimbabwe which is 6 times bigger than that of genotypes. Genotypes G1, G11 and G3 that are higher yielding $\left(>2,233 \mathrm{~kg} \mathrm{ha}^{-1}\right)$ and more stable than the checks, G4 (CBC2) and G7 (CBC3); are candidates for release. Location Harare Research Station is the most ideal testing location for cowpea genotypes in Zimbabwe.

\section{ACKNOWLEDGEMENT}

We are grateful to the Crop Breeding Institute of the Ministry of Agriculture, Mechanisation and Irrigation Development of Zimbabwe for the material support.

\section{REFERENCES}

Alwala, S., Kwolek, T., McPherson, M., Pellow, J. and Meyer, D. 2010. A comprehensive comparison between Eberhart and Russell joint regression and GGE biplot analyses to identify stable and high yielding maize hybrids. Field Crops Research 119:225-230.

Annicchiarico, P., Pecetti, L., Boggini, G. and Doust, M.A. 2000. Repeatability of largescale germplasm evaluation results in durum wheat. Crop Science 40:1810-1814.

Baker, R. 1988. Tests for crossover genotypeenvironmental interactions. Canadian Journal of Plant Science 68:405-410. 
Becker, H. and Leon, J. 1988. Stability analysis in plant breeding. Plant Breeding 101:123.

Bernardo, R. 2002. Breeding for quantitative traits in plants. Stemma Press, Woodbury, USA. 369 pp.

Blanche, S.B. and Myers, G.O. 2006. Identifying discriminating locations for cultivar selection in Louisiana. Crop Science 46:946-949.

Caliskan, M.E., Erturk, E., Sogut, T., Boydak, E. and Arioglu, H. 2007. Genotype x environment interaction and stability analysis of sweetpotato (Ipomoea batatas). genotypes. New Zealand Journal of Crop and Horticultural Science 35:87-99.

Casanoves, F., Baldessari, J. and Balzarini, M. 2005. Evaluation of multienvironment trials of peanut cultivars. Crop Science 45:1826.

CBI. 2012. Annual Technical Reports. Crop Breeding Institute, Harare, Zimbabwe. pp. $14-19$.

Cooper, M. and DeLacy, I. 1994. Relationships among analytical methods used to study genotypic variation and genotype-byenvironment interaction in plant breeding multi-environment experiments. Theoretical and Applied Genetics 88:561572.

Dias, dos. S., Carlos, T. and Krzanowski, W.J. 2003. Model selection and cross validation in additive main effect and multiplicative interaction models. Crop Science 43:865873.

Fatokun, C.A., Tarawali, S.A., Singh, B.B., Kormawa, P.M. and Tamò, M. (Eds.). 2002. Challenges and opportunities for enhancing sustainable cowpea production. Proceedings of the World Cowpea Conference III held at the International Institute of Tropical Agriculture (IITA), Ibadan, Nigeria, 4-8 September 2000. IITA, Ibadan, Nigeria. 433pp.

Gauch, H.G. 2006. Statistical analysis of yield trials by AMMI and GGE. Crop Science 46: 1488-1500.
Gauch, H.G. 2013. A simple protocol for AMMI analysis of yield trials. Crop Science 53:1860-1869.

Gauch, H.G., Piepho, H.P. and Annicchiarico, P. 2008. Statistical analysis of yield trials by AMMI and GGE: Further considerations. Crop Science 48:866-889.

GenStat. 2011. GenStat release 14.0. VSN International Ltd, Hemel Hempstead, United Kingdom.

Gollob, H.F. 1968. A statistical model which combines features of factor analytic and analysis of variance techniques. Psychometrika 33:73-115.

Kaya, Y., Akçura, M. and Taner, S. 2006. GGEbiplot analysis of multi-environment yield trials in bread wheat. Turkish Journal of Agriculture and Forestry 30(5):325-337.

McIntosh, M. 1983. Analysis of combined experiments. Agronomy Journal 75:153155.

Moore, K.J. and Dixon, P.M. 2015. Analysis of combined experiments revisited. Agronomy Journal 107:763-771.

Nyamapfene, K.W. 1991. The soils of Zimbabwe. Nehanda Publishers, Harare, Zimbabwe. 179pp.

Rukuni, M., Tawonezvi, P., Eicher, C., Munyiki-Hungwi, M. and Matondi, P. 2006. Zimbabwe's agriculture revolution. Sable Press, Harare, Zimbabwe. 728pp.

Setimela, P., Chitalu, Z., Jonazi, J., Mambo, A., Hodson, D. and Bänziger, M. 2005. Environmental classification of maizetesting sites in the SADC region and its implication for collaborative maize breeding strategies in the subcontinent. Euphytica 145:123-132.

Yan, W. and Hunt, L. 2001. Interpretation of genotype $\mathrm{x}$ environment interaction for winter wheat yield in Ontario. Crop Science 41:19-25.

Yan, W. and Kang, M.S. 2002. GGE biplot analysis: A graphical tool for breeders, geneticists, and agronomists. CRC press, Boca Raton, London, United Kingdom. 
Yan, W. and Kang, M. 2003. Biplot analysis: A graphical tool for breeders, geneticists and agronomist. CRC Press, Boca Raton, London, United Kingdom.

Yan, W. and Tinker, N.A. 2005. An integrated biplot analysis system for displaying, interpreting, and exploring genotype $x$ environment interaction. Crop Science 45: 1004-1016.

Yan, W. and Tinker, N.A. 2006. Biplot analysis of multi-environment trial data: Principles and applications. Canadian Journal of Plant Science 86:623-645.
Yan, W., Kang, M.S., Ma, B., Woods, S. and Cornelius, P.L. 2007. GGE biplot vs. AMMI analysis of genotype-by-environment data. Crop Science 47:643-653.

Yang, R.C., Crossa, J., Cornelius, P.L. and Burgueño, J. 2009. Biplot analysis of genotype $\mathrm{x}$ environment interaction: Proceed with caution. Crop Science 49: 1564-1576.

Zobel, R.W., Wright, M.J. and Gauch, H.G. 1988. Statistical analysis of a yield trial. Agronomy Journal 80:388-393. 